\title{
Adaption and Selection in C-E Translation of Political Writings
}

\author{
Jinying Leng \\ School of Foreign Languages \\ Easter Liaoning University \\ Dandong, Liaoning, China \\ Email:ljy_angela135@163.com
}

\begin{abstract}
C-E Translation of political writings is one of indispensable elements to achieve China's go global in international communications. Whether Chinese political writings can successfully get access to the English-speaking readers and obtain favorable climate in international community is the major concern of English translation. English translation of Chinese political writing involves what Eco-translatology has always been advocating, the law of "survival of the fittest" and it is believed that the translators and translated texts have to adapt themselves to the ecotranslation environment first, and then make choices in translation process and the translated texts can live in the targeted context. Based on examples of political texts from Chinese policies, Government Work Reports and news in Beijing Review, Chinadaily and other English media in China, it is expected to describe and analyse what has been adapted and selected in the process of translation and hence the suggestions for English translation of Chinese political writings are offered.
\end{abstract}

Keywords: adaption and selection; C-English translation; political writings

\section{INTRODUCTION}

English translation of Chinese political texts has been a long tradition since the foundation of Beijing Review targeted at English speaking foreigners in 1950s'. How to tell the story of China through the mouth of China and communicate with English readers in the favorable way is the major concern of Chinese international communications. In the past several decades, Chinese international communications, or foreign publicity, or overseas publicity, has experienced a lot in order to achieve the effect of it. One of the setbacks of English translation is that English readers do not understand what English news or papers sponsored or produced by China say for a long time. And therefore there are numerous discussions or studies on how to translate Chinese political texts in order to achieve understanding of international communities. It is hoped that English translation of Chinese political writings can be improved under the theory of eco-translatology, which is mainly based on the principle of adaption and selection. Quoting the English translation examples of the political texts from Chinese policies, Government Work Reports and news published in Beijing Review and Chinadaily and other English media in China, the paper will come to analyse how the translators select original texts, translation strategies and adapt to the translation eco-environment and manage to convey the message inherent in the political discourse by means of with eco-translational concepts, since the theory is believed as one of the theories can offer to help achieve the $\mathrm{C}-\mathrm{E}$ translation in international communications.

\section{LITERATURE REVIEW OF ENGLISH} TRANSLATION OF CHINESE POLITICAL WRITINGS

China has to make herself known in the international world in which English is one of the most frequently used language. English translation of Chinese political writings is one crucial part of international communications, which used to be referred as foreign publicities or propaganda. Duan Liancheng and Shen Suru is the first prominent experts working as the editors of newspapers or magazines targeted at English speakers. They have uttered their opinions on English translation of overseas publicity from linguistic point of view since the majority of it belongs to political texts and they have called for readers' acceptability and suggested that political jargons be translated properly instead of literally in the last decade of 20th century. Another famous "Three Close Principles" advocated by Huang Youyi aimed at translation principles, close to Chinese development, English speakers' need and foreigners' thinking. The development of C-E translation of political writings has entered a new era after the 18th Central Committee of the Communist Party of China claimed that China should set up her own saying in international discourse, and tell the story of China successfully. C-E translation of this field has gone beyond word translation, culture, ideology, history and other extralinguistic concepts have been quoted to study the political text translation. Chinese Translators Journal hosted special forums in 2014, like "Discourse System Construction, Overseas Publicity, and Translation", in which translators, editors and officials discussed the challenges of translation of government and diplomatic documents, and its publicity effects on the profile of China in the world. [1] Li Yafang from Beijing Review wrote that one of the obstacles of international communication is overkill, in which translators translated Chinese strictly in form and content. The English readers actually cannot understand what they say. Cai Lijian argued that it was not proper to translate Chinese with rigid faithfulness, and it was necessary to convert paratactic Chinese into hypotactic English according to logics and contexts. Nida's dynamic equivalence was highly recommended in his article. [2] Most of studies conducted by college students in C-E translation of political texts based their arguments upon function of overseas publicities to translation, described or tentatively prescribed certain translation methods and 
strategies under a theory. For example, skopos theory, hermeneutic approach, semantic and communication translation theory and so on are employed in the C-E translation of political texts. Liu Yafeng has discussed and researched the translation process of China's global communication based on translators' adaption and selection. It is admitted that the translation should be steered firmly in seeking common ground on major questions while reserving differences on minor points.

As discussed above, those academic researches and discussions on C-E translation of political texts have contributed to improving translation technique and quality in outward translation tasks in a way or another. However, what is need urgently is to make out a norm as a constant rule to follow in C-E translation of political texts instead of practical advice or suggestions. And hence, the paper is designed to quote adaption and selection in ecotranslatology to study successful English translation of Chinese political writings, since the theory put emphasis on the acceptance of targeted readers which is in line with the purpose of international communications.

\section{ECO-TRANSLATOLOGY}

Nida conceived translation as "reproducing in the receptor language the closest natural equivalent of the source language message..."expounded the response of receptors in evaluating translation, and [Nida, 1964]. [3]Andre Lefevere and Susan Bassnett, however, shifted translation studies to cultural turn in the light of context, history and convention and manipulation of translation process, redefining the object of translation as a contextualized event "embedded within its network of both source and target cultural signs,". The interdisciplinary approach provided a fresh insight on how a text is selected for translation, what role a translator, editor, publisher or patron plays and how a translated text could be received in the targeted language. [4]

Translation researchers then found that culture, history, society and other fields have been introduced and interdisciplinary perspectives were greatly needed to study translation for its broader development. Quoted from Evolution and ecological environmental protection, Ecotranslatology, was put forward by $\mathrm{Hu}$ Gengshen in 2001, explores translation and translation process from the perspective of ecological studies, defining translation as "a series of selective activities by a translator during his/her process to adapt himself/herself to the eco-environment of translation" [5]. He has borrowed the ecological terms of "survival of the fittest", "selection and adaption" "afterward punishment" and etc from what Darwin used to describe the laws of Nature, comparing analogically translation to evolutionary system. The theory thus seems to be a natural outcome of interaction of multi-disciplines.

In his eco-translatology, adaptation-selection stands as the core of the theory, mainly exploring the issues of a translator's/targeted texts' selective adaptation and his/her/its adaptive selection in the translation process. Just like Bassnett put it, how a translator and patron select original texts and how translated versions adapt to the targeted system. The interactions between a translator and the factors concerned in the translation process in the theory are brought under a much deeper and broader condition, an ecological system. All the participants in the translation process make efforts to achieve harmony and balance in translation. The adaptive process includes selection, and the selective process includes adaptation. Translation follows in a way the same modus operandi of Evolution, namely adaptation, selection, and survival of fittest or extinction of weakness. $\mathrm{Hu}$ develops four principles of eco-translation ethics in his latest monograph: the principle of "balance and harmony," the principle of "multiple eco-integration," "symbiosis and diversity", and "translator responsibility" [5]. Here Chinese traditional Daosim has registered its presence in the theory with wellknown saying, "human follows land, land follows sky, sky follows Taoism, and Taoism follows nature."

Eco-environment of translation is what affects existence and survival of all translation entities in the exterior conditions. Translation entities include authors, translators, readers, agents, sponsors, publishers, editors and so on and exterior conditions refer to translationrelated economic, linguistic, cultural, social, historical and political ones. Ecological environment of translation" (or "translation environment") should be "an ideal environment which a translator, translational act and the result of translation etc. are in" [6].

To be short, eco-translation environment is a general environment for a translator and the original and target texts, in which many kinds of factors constrain a translator's optimal adaptation and selection, and the premise and foundation for a translator's multidimensional adaptation and adaptive selection is offered.

\section{ANALYSIS OF C-E TRANSLATION OF POLITICAL WRITINGS IN ECO-TRANSLATION}

Before we move on to describe how a translator select Chinese political texts, to adapt to ecological translation environment and how the translated texts are received by English in C-E political texts, we have to admit that what has undermined the effect of C-E translation of political texts in the past several decades partially is due to set models of linguistic features of Chinese overseas publicity, which is one of the big headaches for translators. In addition to that Chinese political leaders tend to use jargon, numbers, and classic Chinese poetry in their speeches, there are cultural, social and ideological differences between original Chinese and targeted English. Generally speaking, two prevailing tendencies in the translating Chinese characteristic words: one is strict word-for-word translation, the other being overdue liberal translation. For the first kind of translation, translators focused more on Chinese original texts than English speakers' reading habits and capacity. And it is understandable that the political consciousness has to be observed in the first place. On the other hand, over translation and under translation are often resulted in during the C-E political text translation. Such rewriting is often reflected in adding or omitting original information. Hence, this article will study the C-E translation of political texts from an 
ecological environmental perspective in the following aspects.

\section{A. Selection of Chinese Political Texts}

One of the prominent factors affecting the effect of translated versions is the "right" overseas political materials. Since translation of Chinese political texts is targeted at English speaking readers, it is crucial to tell what they want instead of what they hear. In We-media time, the channel and ways to get access to information is beyond our imagination. So it is proper to select what the English readers are interested in and tell the story of China in a favorable way. The majority of readers of Chinese overseas publicities, especially political texts now is consisted of average readers with little or no knowledge of China, compared with those who are expert in language and history of China and those who always share faithful friendship with China in the Continent of Asia and Africa. English average readers still have to learn about China on their mainstream media to, and English translation of Chinese political texts has to conform to their reading habit and literary expectation. As long as we have got the right subjects in translation can we have a saying in disseminating Chinese political texts. So the adaption and selection here can best remind the translators or publicizing patrons of Chinese text selection that what English speaking readers concern most about China is the first priority in translating activity. Even if China have been experiencing a lot of changes since the foundation of PRC in 1949, most average Westerners still do not understand what is "new China" or "the movement to resist U.S. aggression and aid Korea". It doesn't mean that we can not translate Chinese history or other characteristic subjects, rather, we have to care about the international communications and find a way to express China in a effective and smooth way through translation.

\section{B. Adaption and Selection of Translation Strategies}

To achieve adaption and selection in linguistic, cultural and communicative levels during translation is the key to make the translation acceptable. That is, it is the translator who acts as an independent agent to carry out the adaption and selection with all the knowledge and competence of translation. When we come to analyze the C-E translation of political texts, it is safe to start with examples in translation and tell what happened in the process.

As for linguistic level of translation process, “八个坚 持，八个反对” comes first. Chinese leaders prefer numbers in the phrases of "N...X" to publicize the CPC or government regulations or laws among average or low literacy people in a simple way. It used to be translated as "eight adheres and eight opposes" when the policy came out. Although the translation was faithful to the original text, it was difficult for the target language readers to understand what it on earth meant. It is clear that the selection of words here is not proper and the collocation in the translation is strange for English readers. The translation of course is not accepted in English readers, or we say, the ecologically incompatible. The strict literal translation is not desired in the case according to ecological translation environment. Later, it was found that there is English saying "do's and don'ts" which can be equivalent of the Chinese phrase. Now the translation can transplant Chinese policies successfully into English. It is fine that the translator has translated Chinese in line with the original structure, however, the translated version failed to transmit the original meaning of Chinese. That is, Chingish of this kind of collocation that ignore the wholeness of translation processes goes against English expression and it is hard to be understood.

Translators in the eco-translatology play a key role in translation process and they carry out adaption and selection of translation strategies consciously or subconsciously. In the concrete C-E translation of political texts, the connotation of words varies depending on contexts and intention of speakers. At the same time, there exist strict political correctness and standing in overseas publicities, which brings great challenges for translators.

In terms of cultural and communicative levels, we'd like to combine the two aspects together and describe what happened in translation. President Xi Jinping has even uttered that “打铁还需自身硬” in the press conference right after the 18th National Congress of CPC in order to stress the strengthening CPC's building so that the Party can be the leaders of China to establish Chinese characteristic socialism successfully. The sentence on the spot has been rendered as "To be turned into iron, the metal itself must be strong." When we do the back translation, it can be noticed that English translation is different from understanding of Chinese audience because the reflexive pronoun "itself" in the translation would cause ambiguity in referring to the iron, or the hammer, or the blacksmith. There are several English translations to take a look:

1) To forge iron, one must be strong. ( $\mathrm{CNN}$ and New York Times. means that the people have to be strong to strike the iron.

2) The metal itself must be hard to be turned into iron. (BBC) 自身硬 has been translated that the hammer have to be strong. To forge iron, you need a strong hammer. (Daily Telegraph)

3) The ironsmiths must be himself strong for iron work.

All the above translation misses the key information that the blacksmith practice his skills in a continuing way. "Toughen sb. up" is highly recommended here as for the linguistic understanding. Xinhua News Agency has offered a different translation by relating to the context of President Xi's speech and rendered it into "To address these problems, we must first of all conduct ourselves honorable." For English readers, the Chinese idioms with culture and tradition are no longer in the way of their understanding of translation. The semantics and culture in the translation have been omitted under the control of translators. The translator deliberately rewrites the sentence and weakens strange and unusual features for the target culture. This acceptability is also realized via explicating the logic and meaning in the source text and making the target text more cohesive in targeted language. 
The rewriting of culture and manipulating the original texts is conducted according to ecological idea and transmit the intention of speakers.

\section{Adaption of Translators and Translated Texts to the Translation Eco-environment}

In the ecological translation environment, the evaluation of the translation products is directed at the acceptance of the translated versions from the targeted readers. The survival of the translation relies on the comprehension and acceptability of targeted language and culture. That is, if English readers understand translation of Chinese political texts, the translation conform to the textual norms of the targeted culture.

As for survival of the fittest, the translation of “台独” is a typical example. The issue of Taiwan Straits is always the most sophisticated topics in international communities. Whether the term should be translated properly and convey the Mainland of China successfully concerns the diplomatic relation and justify China's stance. English news and other English political publicity texts in mainland China had rendered it simply as "separation, split, division". However, it seemed that we China didn't win support for Chinese reunification during international communication. Things changed greatly when "AntiSecession Law" published by Xinhua News Agency in 2004. Westerners, especially readers in the United States of America began to catch on the term. The connation of "secession" would rightly remind English readers of the Civil War in American history and the universal experience of China's and America's readers is aroused. It is such a successful translation that American media have the tendency to quote the "secession" provided and publicized by mainland China. So, the proper choice of words that translation can express China's real intention is so important and the translation has been accepted and can be compatible in English contexts. So in the ecotranslation environment, the translation has made itself acceptable and adapt itself in the targeted environment.

\section{CONCLUSION}

In conclusion, there are overwhelming articles on discussions of translation from Chinese into English devoted to translation difficulties and associated strategies, and most of them are carried out on the basis of personal translation experiences. One noticeable trend in recent studies on translation of non-literary text in China is that there seems to be strong scholarly interest in issues that go beyond purely practical applications to culture, society, and language. C-E translation of political texts in discussions is more tightly devoted to the pragmatic conditions of production, and their effectiveness is more likely to be evaluated by whether they conform to the textual norms of the target culture under the theory of ecotranslatology.

The problems discussed above mainly address the tendencies in failure of $\mathrm{C}$-E translation, focusing on translation strategies of translators. Of course, there are other elements in the process of translation which would lead to misunderstanding of C-E translation of political texts. For example, the competence and responsibility of translators, cultural and ideological restraint on translation all contribute to the problems in the field. All can actually be included and explicated in the framework of adaption and selection since each element in the whole translation process can be conceived as an entity in the ecological chain. And the main discussion in the paper is dedicated to how to select the translation materials, how to translate the Chinese political texts and how adapt to the targeted contexts.

Therefore, the most important task for C-E translation of political texts is perhaps to combine theoretical research into translation practice so that experts from other related disciplines, be it science, history, culture, publicity, or politics, will participate and collaborate in multidimensional translation activity so as to offer effective solutions to maximize international communications. Thus, the complex role of C-E translation in the production and circulation of Chinese political texts can be understood better.

\section{REFERENCES}

[1] Yang P. Translation Studies in Contemporary China: Retrospect Reflection, and Prospect[M]//Translation and Academic Journals. Palgrave Macmillan US, 2015: 37-66.

[2] L. Cai. On English Translation of Government Official Documents [J]. Chinese Translators Journal. 2015, 36(6): 81-87.

[3] Nida, E. A. \&Taber, R. Charles, The theory and practice of translation, Shanghai Foreign Language Education Press, Shanghai, pp. 1-29, 2004.

[4] Bassnett S, Lefevere A. Constructing cultures: Essays on literary translation[M]. Multilingual Matters, 1998.

[5] G. Hu, Translation as Adaptation and Selection, Hubei Educational Publishing, Wuhan, 2004.

[6] Jiang X. "Eco" and "Adaptation-Selection" in Eco-Translatology Explained[M]//Translation and Academic Journals. Palgrave Macmillan US, 2015: 135-148. 